\title{
Antimalarial properties and molecular docking analysis of compounds from Dioscorea bulbifera L. as new antimalarial agent candidates
}

Prapaporn Chaniad ${ }^{1}$, Mathirut Mungthin ${ }^{2}$, Apirak Payaka ${ }^{3}$, Parnpen Viriyavejakul ${ }^{4}$ and Chuchard Punsawad $^{1 *}$

\begin{abstract}
Background: At present, the emergence and spread of antimalarial drug resistance has become a significant problem worldwide. There has been a challenge in searching for natural products for the development of novel antimalarial drugs. Therefore, this study aims to evaluate compounds from Dioscorea bulbifera responsible for antimalarial properties and investigate potential interactions of the compounds with Plasmodium falciparum lactate dehydrogenase (PfLDH), an essential glycolytic enzyme in the parasite's life cycle.

Methods: An in vitro study of antimalarial activity against chloroquine (CQ)-resistant Plasmodium falciparum (K1 strain) and CQ-sensitive $P$. falciparum (3D7 strain) was performed using the ${ }^{3} \mathrm{H}$-hypoxanthine uptake inhibition method. The cytotoxic effects of the pure compounds were tested against Vero cells using a 3-(4,5-dimethylthiazol2-yl)-2,5-diphenyltetrazolium bromide (MTT) assay. The interactions of the compounds with the PfLDH active site were additionally investigated using a molecular docking method.

Results: Quercetin (6) exhibited the highest antimalarial activity against the $P$. falciparum K1 and 3D7 strains, with $I_{50}$ values of 28.47 and $50.99 \mu \mathrm{M}$, respectively. 2,4,3',5'-Tetrahydroxybibenzyl (9), 3,5-dimethoxyquercetin (4) and quercetin-3-O- $\beta$-D-galactopyranoside (14) also possessed antimalarial effects against these two strains of $P$. falciparum. Most pure compounds were nontoxic against Vero cells at a concentration of $80 \mu \mathrm{g} / \mathrm{ml}$, except for compound 9, which had a cytotoxic effect with a $\mathrm{CC}_{50}$ value of $16.71 \mu \mathrm{M}$. The molecular docking results indicated that 9 exhibited the best binding affinity to the PfLDH enzyme in terms of low binding energy $(-8.91 \mathrm{kcal} / \mathrm{mol})$ and formed strong hydrogen bond interactions with GLY29, GLY32, THR97, GLY99, PHE100, THR101 and ASN140, amino acids as active sites. In addition, 6 also possessed remarkable binding affinity $(-8.53 \mathrm{kcal} / \mathrm{mol})$ to $P f L D$ by interacting with GLY29, ILE31, ASP53, ILE54, THR97 and THR101.

Conclusion: Quercetin is a major active compound responsible for the antimalarial activity of D. bulbifera and is an inhibitor of PfLDH. These findings provide more evidence to support the traditional use of D. bulbifera for malaria treatment. Structural models of its interactions at the PfLDH active site are plausibly useful for the future design of antimalarial agents.
\end{abstract}

Keywords: Malaria, Anti-malarial activity, Dioscorea bulbifera L., Plasmodium falciparum, Molecular docking

\footnotetext{
* Correspondence: chuchard.pu@wu.ac.th

'School of Medicine, Walailak University, Nakhon Si Thammarat 80160,

Thailand

Full list of author information is available at the end of the article
}

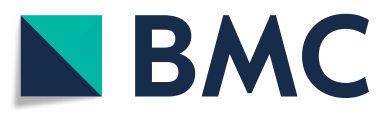

(c) The Author(s). 2021 Open Access This article is licensed under a Creative Commons Attribution 4.0 International License, which permits use, sharing, adaptation, distribution and reproduction in any medium or format, as long as you give appropriate credit to the original author(s) and the source, provide a link to the Creative Commons licence, and indicate if changes were made. The images or other third party material in this article are included in the article's Creative Commons licence, unless indicated otherwise in a credit line to the material. If material is not included in the article's Creative Commons licence and your intended use is not permitted by statutory regulation or exceeds the permitted use, you will need to obtain permission directly from the copyright holder. To view a copy of this licence, visit http://creativecommons.org/licenses/by/4.0/ The Creative Commons Public Domain Dedication waiver (http://creativecommons.org/publicdomain/zero/1.0/) applies to the data made available in this article, unless otherwise stated in a credit line to the data. 


\section{Background}

Malaria remains one of the life-threatening infectious diseases in tropical and subtropical regions of the world [1]. Of the five species of Plasmodium parasites that cause human malaria, Plasmodium falciparum is the most pathogenic species with the greatest likelihood of drug resistance $[2,3]$. According to the World Malaria Report, there were an estimated 228 million cases of malaria and 405,000 deaths worldwide in 2018 [4]. At present, artemisinin-based combination therapies (ACTs) are the first-line treatment that has been recommended by the World Health Organization (WHO) for uncomplicated falciparum malaria in all endemic countries. Unfortunately, the emergence and spreading of artemisinin (ART)-resistant $P$. falciparum has already been reported in Southeast Asian countries, including Thailand, Africa and many other malaria endemic countries $[5,6]$. The lack of an effective vaccine for malaria prevention and the widespread use of multidrugresistant $P$. falciparum [7] have led to the urgent need to identify lead compounds and develop new alternative antimalarial drugs to possibly avoid problems related to drug resistance [8].

Plasmodium falciparum lactate dehydrogenase $(P f L D H)$ is an essential enzyme in the parasite's life cycle for survival and growth. It controls the production of adenosine triphosphate (ATP) by catalyzing the conversion of lactate to pyruvate in the final step of the glycolytic pathway during the anaerobic erythrocytic stages of the P. falciparum life cycle [9]. The inhibition of PfLDH leads to parasite death, suggesting a potential antimalarial target [10]; therefore, this enzyme is an attractive target for the design and discovery of antimalarial drugs.

Medicinal plants are a potential source for the discovery and development of new drugs since they contain various metabolites with a great variety of structures and pharmacological activities [11]. The widespread use of medicinal plants in the treatment of malaria with the discovery of two antimalarial drugs, quinine from the bark of a cinchona tree and artemisinin from Artemisia annua L., which are used worldwide [12, 13]. Therefore, in the search for drug candidates, medicinal plants are an alternative potential source to provide new antimalarial agents.

Dioscorea bulbifera L. is a traditional medicinal plant that is used for the treatment of malaria, diarrhea, diabetes, sore throat, gastric cancer, and wound infections and is also used in longevity preparations $[14,15]$. It belongs to the Dioscoreaceae family, which is commonly known as air potato. Various extracts of this plant have been reported to possess various pharmacological effects, such as analgesic, anti-inflammatory [16], antioxidant [17], antimicrobial [18], antidiabetic [15], antihyperglycemic, antidyslipidemic [19] and anti-HIV-1 integrase activities [20, 21]. Remarkably, there have been no reports of any antimalarial activity from $D$. bulbifera until now. Therefore, this study aims to identify compounds from $D$. bulbifera responsible for antimalarial properties and investigate potential interactions of the compounds with PfLDH, a target enzyme associated with the life cycle of malaria.

\section{Materials and methods}

\section{Parasite culture and maintenance}

Chloroquine (CQ)-resistant P. falciparum (K1 strain) and CQ-sensitive P. falciparum (3D7 strain) were kindly provided by the Department of Parasitology, Phramongkutklao College of Medicine, Thailand. The culture of $P$. falciparum malaria parasites was continuously performed using standard methods [22] with some modifications. RPMI-1640 medium was supplemented with noninfected type O-positive red blood cells ( $2 \%$ hematocrit), $2 \mathrm{mg} / \mathrm{ml}$ sodium bicarbonate, $10 \mu \mathrm{g} / \mathrm{ml}$ hypoxanthine (Sigma-Aldrich, New Delhi, India), 4.8 $\mathrm{mg} / \mathrm{ml}$ HEPES (Himedia, Mumbai, India), 10\% human $\mathrm{AB}$ serum and $2.5 \mu \mathrm{g} / \mathrm{ml}$ gentamicin (Sigma-Aldrich, New Delhi, India) [23].

\section{Extraction and isolation of compounds from plant material}

Bulbils of $D$. bulbifera were collected from Uttaradit Province, Thailand, in 2011. The botanical material was identified by a botanist of the Forest Herbarium, Wildlife and Plant Conservation, Thailand. The plant specimen has been deposited in the Department of Pharmacognosy and Pharmaceutical Botany, Faculty of Pharmaceutical Sciences, Prince of Songkla University, Hat-Yai, Songkhla, Thailand with a voucher specimen of SKP 062040201.

According to previous reports by our research group, compounds 1-14 were purified from the ethanol extract of $D$. bulbifera bulbils by chromatography techniques and elucidated by spectroscopic methods [20, 21]. Briefly, ethanol extract by maceration method was successively partitioned with various solvents to give chloroform, ethyl acetate and water fractions. The chloroform fraction was separated by vacuum liquid chromatography (VLC), column chromatography (CC), preparative thin layer chromatography (PTLC) and Sephadex LH-20 to give seven compounds, including 8-epidiosbulbin $\mathrm{E}$ acetate (1), 15,16-epoxy- $6 \alpha$-O-acetyl-8 8 -hydroxy-19-norclero-13(16),14-diene-17,12;18,2-diolide (2), sitosterol- $\beta$ D-glucoside (3), 3,5-dimethoxy quercetin (4), (+)-catechin (5), quercetin (6) and kaempferol (7). The ethyl acetate fraction was separated by VLC, CC and Sephadex LH-20 to provide allantoin (8), 2,4,3',5'-tetrahydroxybibenzyl (9), 2,4,6,7-tetrahydroxy-9,10-dihydrophenanthrene (10), myricetin (11) and 5,7,4' -trihydroxy-2-styrylchromone (12). In 
addition, the water fraction was fractionated on a Diaion HP-20 column and further isolated through an RP-18 column and Sephadex LH-20 to give quercetin-3-O- $\beta$-D-glucopyranoside (13) and quercetin-3-O- $\beta$-D-galactopyranoside (14). The chemical structures of the compounds were characterized by EI-MS and NMR spectroscopic methods, including ${ }^{1} \mathrm{H}-\mathrm{NMR},{ }^{13} \mathrm{C}-\mathrm{NMR}$, DEPT, COSY, HMQC, $\mathrm{HMBC}$ and comparison with data in the literature. In the present study, the extracts and 14 compounds (1-14) from a previous study were investigated for antimalarial activity (Fig. 1).

\section{Antimalarial activity assay}

Antimalarial activity of extracts and compounds from $D$. bulbifera against $P$. falciparum $\mathrm{K} 1$ and $3 \mathrm{D} 7$ strains were assessed by measuring ${ }^{3} \mathrm{H}$-hypoxanthine incorporated in parasite nucleic acids using the modified technique of Desjadins et al. [24]. The red cell suspension at $1-2 \%$ hematocrit containing $1 \%$ ring stage $P$. falciparum-infected red blood cells was incubated with various concentrations of extracts $(2.50-80 \mu \mathrm{g} / \mathrm{ml})$ and pure compounds $(2.5-80 \mu \mathrm{M})$ in 96 -well culture plates. Parasites were incubated at $37^{\circ} \mathrm{C}$ for $24 \mathrm{~h}$, then ${ }^{3} \mathrm{H}$-hypoxanthine $(25 \mu \mathrm{l}$ of $0.025 \mu \mathrm{Ci} / \mu \mathrm{l})$ was added to each well, and the plates were maintained under conditions of $93 \% \mathrm{~N}_{2}$, $3 \% \mathrm{O}_{2}$ and $4 \% \mathrm{CO}_{2}$ at $37^{\circ} \mathrm{C}$ for an additional $24 \mathrm{~h}$. The samples were transferred to a glass fiber filter (Wallac, Turku, Finland). ${ }^{3} \mathrm{H}-\mathrm{Hypoxanthine} \mathrm{uptake} \mathrm{was} \mathrm{then}$ assessed using a MicroBeta TriLux Liquid Scintillation Counter (PerkinElmer, USA). Each assay condition was performed in triplicate independently. The concentration of samples that inhibited the uptake of ${ }^{3} \mathrm{H}$ -

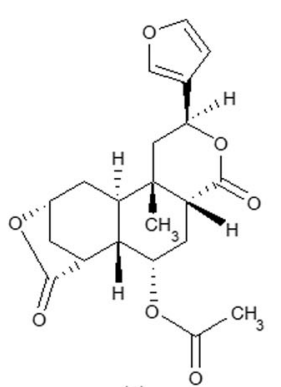

(1)<smiles>COc1cc(O)cc2oc(-c3ccc(O)c(O)c3)c(O)c(=O)c12</smiles>

(4)<smiles>O=c1c(O)c(-c2ccc(O)cc2)oc2cc(O)cc(O)c12</smiles>

(7)

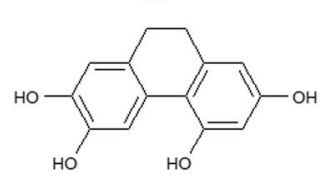

(10)

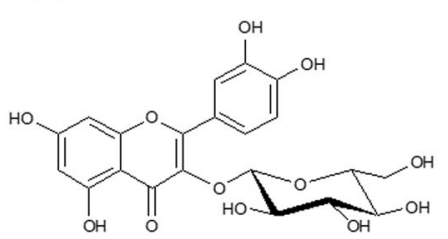

(13)<smiles>CC(=O)O[C@H]1C[C@]2(C)C(=O)O[C@H](c3ccoc3)C[C@]2(O)[C@H]2C[C@@H]3C[C@H]1C(=O)O[C@H]23</smiles>

(2)<smiles>Oc1cc(O)c2c(c1)O[C@H](c1ccc(O)c(O)c1)[C@H](O)C2</smiles>

(5)<smiles>NC(=O)NC1NC(=O)NC1=O</smiles>

(8)<smiles>O=c1c(O)c(-c2cc(O)c(O)c(O)c2)oc2cc(O)cc(O)c12</smiles>

(11)

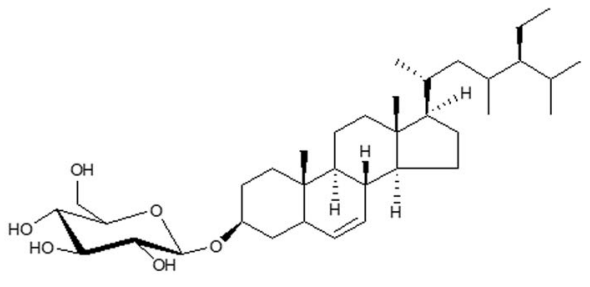

(3)<smiles>O=c1c(O)c(-c2ccc(O)c(O)c2)oc2cc(O)cc(O)c12</smiles>

(6)<smiles>Oc1cc(O)cc(CCc2ccc(O)cc2O)c1</smiles>

(9)<smiles>O=c1c(O)c(/C=C/c2ccc(O)cc2)oc2cc(O)cc(O)c12</smiles>

(12)<smiles></smiles>

(14)

Fig. 1 The structures of compounds isolated from D. bulbifera bulbils 
hypoxanthine by $50 \%\left(\mathrm{IC}_{50}\right)$ assessed by log dose response curve using WinNonlin software version 4.1 (Pharsight Corporation, CA) was used as a marker of antimalarial effect potency. Artesunate at concentrations ranging from $0.1-20 \mathrm{nM}$ and chloroquine at concentrations ranging from $2.0-250 \mathrm{nM}$ were used as positive controls.

\section{In vitro assessment of cytotoxicity}

The toxicity of D. bulbifera extracts and isolated compounds was assessed by 3-(4,5-dimethythiazol-2-yl)-2,5diphenyl tetrazolium bromide (MTT) assay according to a previous method [23]. Briefly, Vero cells (Elabscience, Wuhan, Hubei, China) were seeded into 96-well plates at a density of $10^{4}$ cell $/ \mathrm{ml}$ and incubated for $24 \mathrm{~h}$ at $37^{\circ} \mathrm{C}$ with $5 \% \mathrm{CO}_{2}$. Cells were then treated with various concentrations of extracts and compounds for $48 \mathrm{~h}$ at $37^{\circ} \mathrm{C}$ with $5 \% \mathrm{CO}_{2}$. Doxorubicin (Sigma-Aldrich, New Delhi, India) was used as a toxic control. Subsequently, MTT solution was added to each well, and the plate was incubated for $2 \mathrm{~h}$ in a $\mathrm{CO}_{2}$ incubator. The medium was then removed, and $100 \mu \mathrm{l}$ of DMSO was added to each well. Finally, the optical density was determined at a wavelength of $590 \mathrm{~nm}$ using a microplate reader. The assay was performed in duplicate.

\section{Molecular docking \\ PfLDH structure preparation}

The 3D structure of PfLDH (residues ALA18-ALA329) in complex with $\beta$-nicotinamide adenine dinucleotide phosphate disodium salt (NADH) and oxamate was obtained from the Protein Data Bank (PDB code 1LDG). The PfLDH structure was prepared using AutoDock Tools. The missing residues were incorporated. All water molecules and oxamate, a competitive inhibitor of the binding of pyruvate to $\mathrm{LDH}$ and $\mathrm{NADH}$ cofactor, were removed so that a new ligand could enter the active site [10].

\section{Ligand molecule preparation}

The 3D structures of compounds 1-14, artesunate and chloroquine were generated using the HyperChem Professional 8.0 program. (Hypercube Inc., Gainesville, FL). Each structure was geometrically optimized using the semiempirical PM3 method. Subsequently, Gasteiger charges were assigned to the ligands using AutoDock Tools to model the appropriate structures for docking calculations.

\section{Molecular docking analysis}

Molecular docking calculations were performed according to a previous method [25] using the AutoDock 4.2 program (Hypercube Inc., Gainesville, FL). The PfLDH active site was selected as the ligand binding site. A grid box size of $60 \times 60 \times 60 \AA^{3}$ was generated and centered on 32,30 and $32 \mathrm{~A}^{\circ}$ for $\mathrm{x}, \mathrm{y}$, and $\mathrm{z}$, respectively, with a grid spacing of $0.375 \AA$. The Lamarckian genetic algorithm (LGA) was performed with the rigid receptor molecule to search for the best conformers. The docking run was set at a maximum of 100 conformations for each ligand. The population size was set at 150 , the maximum number of energy evaluations was increased to $2,500,000$, and the genetic generation was 100,000 . The other parameters were set to default values of AutoDock 4.2. The docking methodology was evaluated by redocking to achieve more accurate results. The lowest binding energy conformation of the most populated cluster was considered the best-docked conformation that was chosen for analysis of the hydrogen bond interactions [20]. The 3D H-bond interactions between compounds and the binding site of the enzyme were generated by the UCSF Chimera 1.14 program, and hydrophobic interactions were evaluated using the protein ligand interaction profiler (PLIP) [26].

\section{Results}

\section{Antimalarial property against $P$. falciparum $\mathrm{K} 1$ strain}

The ethanol extract of $D$. bulbifera exhibited good activity against the $P$. falciparum $\mathrm{K} 1$ strain with an $\mathrm{IC}_{50}$ value of $15.8 \mu \mathrm{g} / \mathrm{ml}$, while the water extract showed weak activity $\left(\mathrm{IC}_{50}>80 \mu \mathrm{g} / \mathrm{ml}\right)$. Among 14 tested compounds, quercetin (6) possessed the highest effect with good activity $\left(\mathrm{IC}_{50}=28.47 \mu \mathrm{M}\right)$ and showed $97.01 \%$ inhibition at a concentration of $80 \mu \mathrm{M}$, followed by $2,4,3^{\prime}, 5^{\prime}$-tetrahydroxybibenzyl $\left(9, \mathrm{IC}_{50}=39.99 \mu \mathrm{M}\right)$. 3,5-Dimethoxyquercetin (4), quercetin-3-O- $\beta$-D-galactopyranoside (14), 2,4, 6,7-tetrahydroxy-9,10-dihydrophenanthrene (10) and kaempferol (7) also exhibited antimalarial effects with moderate activity with $\mathrm{IC}_{50}$ values of $44.03,48.33,58.34$ and $62.45 \mu \mathrm{M}$, respectively (Table 1), whereas the other compounds were apparently weakly active $\left(\mathrm{IC}_{50}>80 \mu \mathrm{M}\right)$.

\section{Antimalarial property against $P$. falciparum 3D7 strain}

The results for the $P$. falciparum 3D7 strain were similar in the K1 strain; quercetin (6) also possessed the highest antimalarial activity $\left(\mathrm{IC}_{50}=50.99 \mu \mathrm{M}\right)$, followed by 2,4 , $3^{\prime}, 5^{\prime}$-tetrahydroxybibenzyl (9), quercetin-3-O- $\beta$-D-galactopyranoside (14) and 3,5-dimethoxyquercetin (4), with $\mathrm{IC}_{50}$ values of $58.85,68.93$ and $70.79 \mu \mathrm{M}$, respectively (Table 1).

\section{In vitro cytotoxicity}

Most pure compounds revealed nontoxic effects on Vero cells at a concentration of $80 \mu \mathrm{g} / \mathrm{ml}$ except for $2,4,3^{\prime}, 5^{\prime}$ tetrahydroxybibenzyl (9), which had cytotoxic effects with a $50 \%$ cytotoxic concentration $\left(\mathrm{CC}_{50}\right)$ value of $16.71 \mu \mathrm{M}$ (Table 1). 
Table 1 Antimalarial properties against P. falciparum K1 and 3D7 strains and the cytotoxicity of extracts and isolated compounds from D. bulbifera

\begin{tabular}{|c|c|c|c|}
\hline \multirow[t]{2}{*}{ Samples } & \multicolumn{2}{|l|}{$I C_{50}\left(\mu M / n^{d}\right)$} & \multirow{2}{*}{$\begin{array}{l}C_{50} \\
(\mu \mathrm{M})\end{array}$} \\
\hline & K1 & 3D7 & \\
\hline Ethanol extract ${ }^{\mathrm{c}}$ & $15.8 \pm 3.18$ & $>80$ & $>80$ \\
\hline Water extract ${ }^{c}$ & $>80$ & $>80$ & $>80$ \\
\hline 8-Epidiosbulbin E acetate (1) & $>80$ & $>80$ & $>80$ \\
\hline 15,16-Epoxy-6a-O-acetyl-8ß-hydroxy-19-nor-clero-13 (16),14-diene-17,12;18,2-diolide (2) & $>80$ & $>80$ & $>80$ \\
\hline Sitosterol- $\beta$-D-glucoside (3) & $>80$ & $>80$ & $>80$ \\
\hline 3,5-Dimethoxyquercetin (4) & $44.03 \pm 1.47^{\mathrm{a}, \mathrm{b}}$ & $70.79 \pm 2.32^{\mathrm{a}, \mathrm{b}}$ & $>80$ \\
\hline (+)-Catechin (5) & $>80$ & $>80$ & $>80$ \\
\hline Quercetin (6) & $28.47 \pm 0.90^{\mathrm{a}, \mathrm{b}}$ & $50.99 \pm 7.28^{\mathrm{a}, \mathrm{b}}$ & $>80$ \\
\hline Kaempferol (7) & $62.45 \pm 1.33^{\mathrm{a}, \mathrm{b}}$ & $>80$ & $>80$ \\
\hline Allantoin (8) & $>80$ & $>80$ & $>80$ \\
\hline 2,4,3',5'-Tetrahydroxybibenzyl (9) & $39.99 \pm 2.50^{\mathrm{a}, \mathrm{b}}$ & $58.85 \pm 4.31^{\mathrm{a}, \mathrm{b}}$ & 16.71 \\
\hline 2,4,6,7-Tetrahydroxy-9,10-dihydrophenanthrene (10) & $58.34 \pm 1.96^{\mathrm{a}, \mathrm{b}}$ & $>80$ & $>80$ \\
\hline Myricetin (11) & $>80$ & $>80$ & $>80$ \\
\hline 5,7,4'-Trihydroxy-2-styrylchromone (12) & $>80$ & $>80$ & $>80$ \\
\hline Quercetin-3-O- $\beta$-D-glucopyranoside (13) & $>80$ & $>80$ & $>80$ \\
\hline Quercetin-3-O- $\beta$-D-galactopyranoside (14) & $48.33 \pm 1.21^{\mathrm{a}, \mathrm{b}}$ & $68.93 \pm 4.31^{\mathrm{a}, \mathrm{b}}$ & $>80$ \\
\hline Chloroquine $^{d}$ & $103.2 \pm 4.50$ & $9.91 \pm 0.56$ & ND \\
\hline Artesunate $^{d}$ & $0.53 \pm 0.04$ & $1.81 \pm 0.19$ & ND \\
\hline Doxorubicin & ND & ND & $1.96 \pm 0.11$ \\
\hline
\end{tabular}

ND not determined

${ }^{a}$ Statistically significant difference between chloroquine and the sample, $p<0.05$ (mean \pm S.D. of three determinations)

${ }^{b}$ Statistically significant difference between artesunate and the sample, $p<0.05$ (mean \pm S.D. of three determinations)

${ }^{c}$ Concentration of treated samples and $\mathrm{IC}_{50}$ unit expressed in $\mu \mathrm{g} / \mathrm{ml}$

${ }^{\mathrm{d}}$ Concentration of positive control and $\mathrm{IC} \mathrm{C}_{50}$ unit expressed in $\mathrm{nM}$

\section{Molecular docking}

To predict the potential interactions of compounds with PfLDH enzyme targets, molecular docking calculations were performed. The binding energy and amino acid residues of $P f L D H$ that interacted with each compound and the hydrogen bonds are given in Table 2. The binding energy with a higher negative value corresponds to a more stable interaction between the compound and target enzyme. To predict the binding modes of active compounds with PfLDH and identify the interacting amino acid residues, the $2 \mathrm{D}$ interactions of the top four active compounds (4, 6, 9 and 14) with PfLDH were created, as shown in Fig. 2. Among the 14 compounds, 2,4, 3',5' -tetrahydroxybibenzyl (9), which possessed a good antimalarial effect $\left(\mathrm{IC}_{50}=39.99 \mu \mathrm{M}\right)$, exhibited the best binding affinity to PfLDH in terms of a low binding energy of $-8.91 \mathrm{kcal} / \mathrm{mol}$; however, its binding energy was lower than that of artesunate $(-11.21 \mathrm{kcal} / \mathrm{mol})$. It is predicted to strongly interact with eight hydrogen bonds with GLY29, GLY32, THR97, GLY99, PHE100, THR101 and ASN140 (Fig. 2e). Additionally, compound 9 was stabilized through hydrophobic interactions with residues THR101, LEU112 and ASN140 (Table 2). For artesunate, the potent antimalarial drug interacted with ILE31, GLY29, GLY32, ILE54, THR97, and GLY99 of the PfLDH active site (Fig. 2a) and formed hydrophobic interactions with VAL26, ILE31, PHE52, ILE54, ALA98, THR101, and ILE119 (Table 2). While chloroquine possessed a weak interaction, it formed only one hydrogen bond with GLY99 with a binding energy of $-6.65 \mathrm{kcal} /$ mol. (Fig. 2b) as well as hydrophobic interactions with VAL26, ILE31, PHE52, THR101 and ILE119.

Interestingly, quercetin (6), which possessed the strongest antimalarial activity against $P$. falciparum $\mathrm{K} 1$ and 3D7 strains in vitro, also showed a remarkable binding affinity to PfLDH with a binding energy of $-8.53 \mathrm{kcal} /$ mol. Its structure fits well to the active site of $P f L D H$, as demonstrated in Fig. 2d. All five hydroxyl groups of quercetin formed eight hydrogen bonds with the enzyme target, including GLY29, ILE54, THR97, and THR101, and strongly interacted with ILE31 and ASP53 with two hydrogen bonds each. Furthermore, quercetin (6) also formed hydrophobic interactions with MET30 and ALA98. 3,5-Dimethoxyquercetin (4), which possessed moderate activity against the $P$. falciparum $\mathrm{K} 1$ strain $\left(\mathrm{IC}_{50}=44.03 \mu \mathrm{M}\right)$, had a slightly lower binding energy 
Table 2 The binding energy and interacting amino acid residues of compounds from D. bulbifera with PfLDH

\begin{tabular}{|c|c|c|c|c|c|}
\hline \multirow[t]{2}{*}{ Compounds } & \multirow{2}{*}{$\begin{array}{l}\text { Binding } \\
\text { energy } \\
\text { (kcal/ } \\
\text { mol) }\end{array}$} & \multicolumn{2}{|c|}{$\mathrm{H}$-bond interaction } & \multicolumn{2}{|c|}{ Hydrophobic interaction } \\
\hline & & $\begin{array}{l}\text { Number of } \\
\text { interaction }\end{array}$ & Amino acid residues & $\begin{array}{l}\text { Number of } \\
\text { interaction }\end{array}$ & Amino acid residues \\
\hline 1 & -7.10 & 4 & ILE31 ${ }^{\mathrm{a}}, \mathrm{ASN} 140, \mathrm{SER} 245$ & 5 & ILE31, THR97, THR101, VAL138, PRO250 \\
\hline 2 & -6.98 & 7 & MET30 a ILE31, THR97, GLY99, ASN140 & 0 & - \\
\hline 3 & -7.33 & 5 & PHE100a, ASN140a, SER245 & 6 & ILE31, ILE54a , VAL55, ALA98, ILE119 \\
\hline 4 & -7.55 & 7 & SER28, ILE31, ASP53 ${ }^{\mathrm{b}}$, PHE100, ASN140 & 1 & THR101 \\
\hline 5 & -7.66 & 8 & $\begin{array}{l}\text { ILE31, GLY32, GLY99, PHE100, THR101, } \\
\text { ASN140", SER245 }\end{array}$ & 2 & THR97, THR101 \\
\hline 6 & -8.53 & 8 & $\begin{array}{l}\text { GLY29, ILE31 }{ }^{\mathrm{a}} \text {, ASP53 }{ }^{\mathrm{a}} \text {, ILE54, THR97, } \\
\text { THR101 }\end{array}$ & 2 & MET30, ALA98 \\
\hline 7 & -7.16 & 8 & $\begin{array}{l}\text { PHE100, ARG109, ASN140a , ASN166, } \\
\text { ARG171, SER245, PRO246 }\end{array}$ & 6 & $\begin{array}{l}\text { THR101, TRP107 }{ }^{a}, \text { ASN140, LEU167, } \\
\text { ALA236 }\end{array}$ \\
\hline 8 & -5.09 & 9 & GLY29, ILE31 ${ }^{a}$, GLY32, THR97ª , GLY99 ${ }^{\mathrm{b}}$ & 0 & - \\
\hline 9 & -8.91 & 8 & $\begin{array}{l}\text { GLY29, GLY32, THR97, GLY99a, PHE100, } \\
\text { THR101, ASN140 }\end{array}$ & 3 & THR101, LEU112, ASN140 \\
\hline 10 & -6.64 & 5 & GLY29, ILE31, GLY32, THR97ª & 2 & ILE31, THR101 \\
\hline 11 & -6.55 & 7 & $\begin{array}{l}\text { GLY29, GLY32, THR97, GLY99, PHE100, } \\
\text { VAL138, PRO246 }\end{array}$ & 4 & ILE31, THR97, THR101, VAL138 \\
\hline 12 & -7.89 & 6 & GLY99a, PHE100, ASN140, SER245 ${ }^{a}$ & 4 & ILE31 ${ }^{\mathrm{a}}$, LEU112, ASN140 \\
\hline 13 & -6.88 & 6 & PHE52, ASP53, ILE54, GLY99a', LYS118 & 9 & $\begin{array}{l}\text { VAL26, PHE52, ILE54, ALA98, LYS118, } \\
\text { ILE119, GLU122, ILE123 }\end{array}$ \\
\hline 14 & -7.86 & 7 & GLY29, ILE31'a GLY32, THR97, GLY99 ${ }^{a}$ & 3 & ILE54, ALA98, THR101 \\
\hline Artesunate & -11.21 & 7 & ILE31, GLY29, GLY32, ILE54a , THR97, GLY99 & 9 & $\begin{array}{l}\text { VAL26, ILE31, PHE52, ILE54 } 4^{\mathrm{a}} \text {, ALA98, } \\
\text { THR101, ILE119 }\end{array}$ \\
\hline Chloroquine & -6.65 & 1 & GLY99 & 6 & VAL26, ILE31'a PHE52, THR101, ILE119 \\
\hline
\end{tabular}

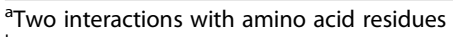

${ }^{\mathrm{b}}$ Three interactions with amino acid residues

$(-7.55 \mathrm{kcal} / \mathrm{mol})$ and formed seven hydrogen bonds with ILE31, ASP53, PHE100, ASN140 and SER28 (Fig. 2c). A remarkable result was also observed with kaempferol (7), a compound that showed moderate antimalarial activity against the $P$. falciparum $\mathrm{K} 1$ strain $\left(\mathrm{IC}_{50}=62.45 \mu \mathrm{M}\right)$. This compound strongly interacted with residues in the active site region of $P f \mathrm{LDH}$ with a binding energy of $7.16 \mathrm{kcal} / \mathrm{mol}$. It formed eight hydrogen bonds with PHE100, ARG109, ASN140, ASN166, ARG171, SER245 and PRO246. Kaempferol (7) formed additional hydrophobic interactions with THR101, TRP107, ASN140, LEU167 and ALA236.

In particular, compounds 4, 5, 6, 7 and 11, which were identified as flavonoids and possessed different antimalarial effects with $\mathrm{IC}_{50}$ values of $44.03,>80,28.47,62.45$ and $>80 \mu \mathrm{M}$, respectively, also presented different binding modes, while their binding locations were similar (Fig. 3). Quercetin (6), the strongest compound, showed a different binding pattern than the other compounds. It directly pointed to ASP53 and interacted tightly with two hydrogen bonds. Quercetin-3-O- $\beta$-D-glucopyranoside (13) and quercetin-3-O- $\beta$-D-galactopyranoside (14) were identified as quercetin glycosides; they showed different binding energies of -6.88 and $-7.86 \mathrm{kcal} / \mathrm{mol}$, respectively, and interacted with different amino acid residues. Compound 14, which exhibited higher activity against the $\mathrm{K} 1$ strain $\left(\mathrm{IC}_{50}=48.88 \mu \mathrm{M}\right)$ than compound $13\left(\mathrm{IC}_{50}>80 \mu \mathrm{M}\right)$, interacted with residues GLY29, ILE31, GLY32, THR97, GLY99 through seven hydrogen bonds (Fig. 2f), while 13 formed six hydrogen bonds with PHE52, ASP53, ILE54, GLY99 and LYS118. These docking results were related to its antimalarial activity, which was determined by an in vitro hypoxanthine assay model. Based on the results of the antimalarial effect against the $P$. falciparum $\mathrm{K} 1$ strain in the in vitro model, compounds $1,2,3,5,8,11,12$ and 13, which are considered inactive compounds $\left(\mathrm{IC}_{50}>80 \mu \mathrm{M}\right)$, were mostly weaker interactions with the PfLDH enzyme than those of active compounds in terms of binding energy and number of hydrogen bonds.

\section{Discussion}

The main obstacle of malaria treatment and control is the emergence of drug-resistant parasite strains, which include artemisinin, the first-line drug for treating uncomplicated multidrug-resistant falciparum malaria [27]. 

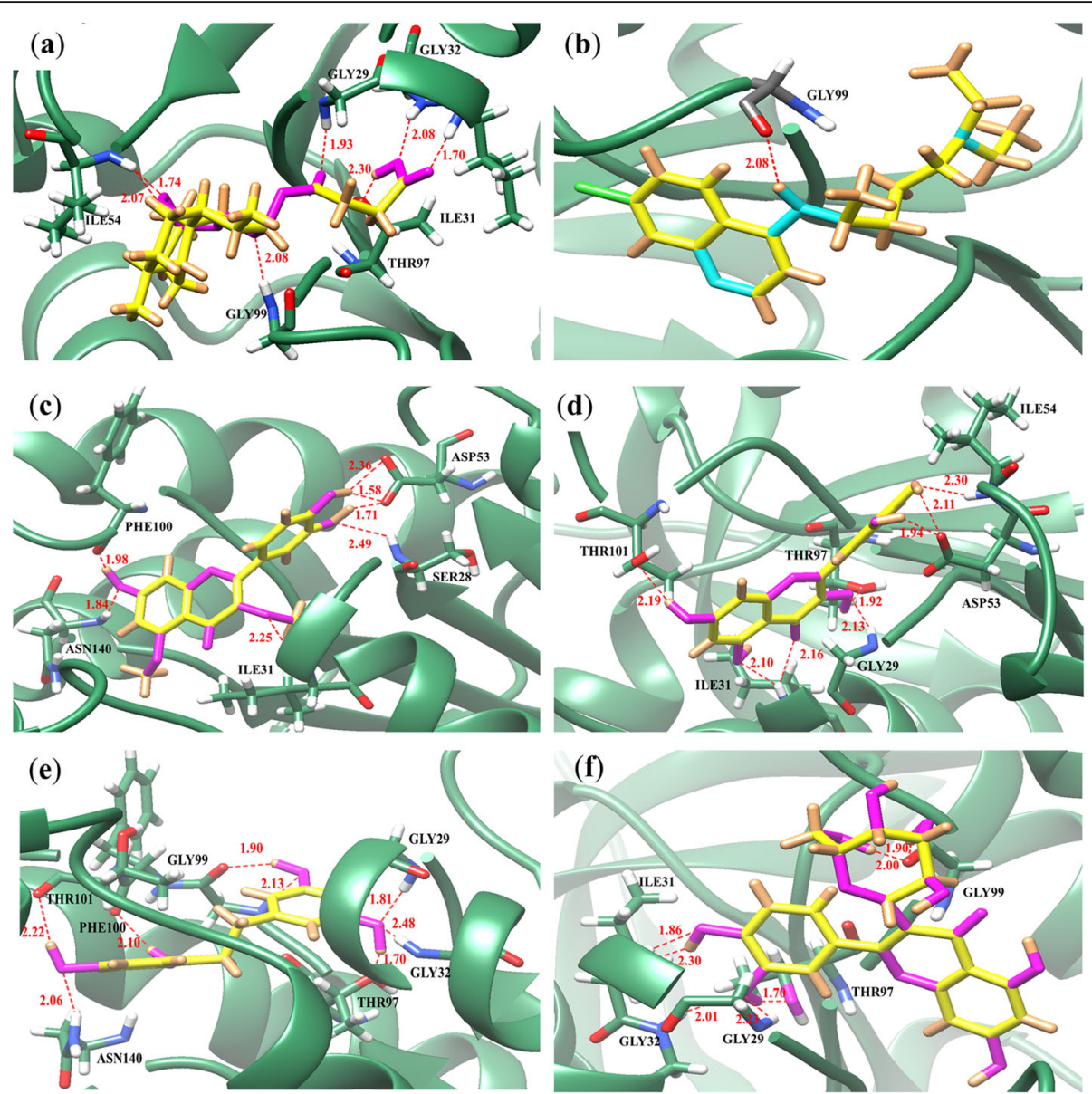

Fig. 2 Predicted binding modes of active compounds, artesunate and chloroquine with PfLDH. The backbones of PfLDH enzyme are depicted in green ribbon models and all hydrogen bonding residues are shown as stick models and labeled by heteroatom; white for $\mathrm{H}$, blue for $\mathrm{N}$, red for $\mathrm{O}$. Compounds are labeled by heteroatom; yellow for $\mathrm{C}$, brown for $\mathrm{H}$, cyan for $\mathrm{N}$, magenta for O. Hydrogen bond interactions are shown as red dash lines and represent bond length in angstrom $\left(A^{\circ}\right)$. a Artesunate. b Chloroquine. c 3,5-Dimethoxyquercetin. d Quercetin. e 2,4,3',5'-

Tetrahydroxybibenzyl. f Quercetin-3-O- $\beta$-D-galactopyranoside

To resolve the problem of multidrug resistance, it is necessary to identify new alternative antimalarial agents with higher activity. In the present study, ethanol and water extracts along with 14 isolated compounds of $D$. bulbifera bulbils were investigated in P. falciparum K1 and 3D7 strains. The results revealed that the ethanol extract possessed a good antimalarial effect $\left(\mathrm{IC}_{50}=\right.$ $15.8 \mu \mathrm{g} / \mathrm{ml}$ ) against the $\mathrm{K} 1$ strain. Among the 14 tested compounds, quercetin, a flavonoid compound, was the most active on the two strains of $P$. falciparum, with $\mathrm{IC}_{50}$ values of 28.47 and $50.99 \mu \mathrm{M}$ for the $\mathrm{K} 1$ and 3D7 strains, respectively. Notably, the antimalarial effect of all compounds against the $\mathrm{K} 1$ strain was higher than that of the 3D7 strain. This effect could be due to the difference in genetics between these two parasite strains [28].

Considering the effect of seven flavonoid compounds $(4,5,6,7,11,13,14)$, the results showed that quercetin (6) possessed the most potent antimalarial effect against both K1 and 3D7 strains. It showed potent activity approximately 1.5 - and 2 -fold higher than that of 3,5dimethoxyquercetin (4) and quercetin-3-O- $\beta$-D-galactopyranoside (14), respectively, which was observed in the K1 strain. Regarding the structure-activity relationships, quercetin (6), an aglycone bearing a catechol moiety in the B-ring and lacking a glycoside chain, exhibited relatively higher activity than its derivatives, as observed from the comparison of quercetin $\left(6 ; \mathrm{IC}_{50}=28.47 \mu \mathrm{M}\right)$ and 3,5-dimethoxyquercetin $\left(4 ; \mathrm{IC}_{50}=44.03 \mu \mathrm{M}\right)$ for the K1 strain. The result was also clearly observed when quercetin (6) was compared with quercetin glycosides (13 and 14, IC $\mathrm{IC}_{50}=100$ and $48.33 \mu \mathrm{M}$, respectively). These results are in agreement with a previous study reporting that quercetin exhibited antimalarial activity higher than that of quercetin glycosides to inhibit the growth of P. falciparum K1 and 3D7 strains [29]. Quercetin was found in a variety of fruits and vegetables and in medicinal plants, including Ginkgo biloba, Hypericum 


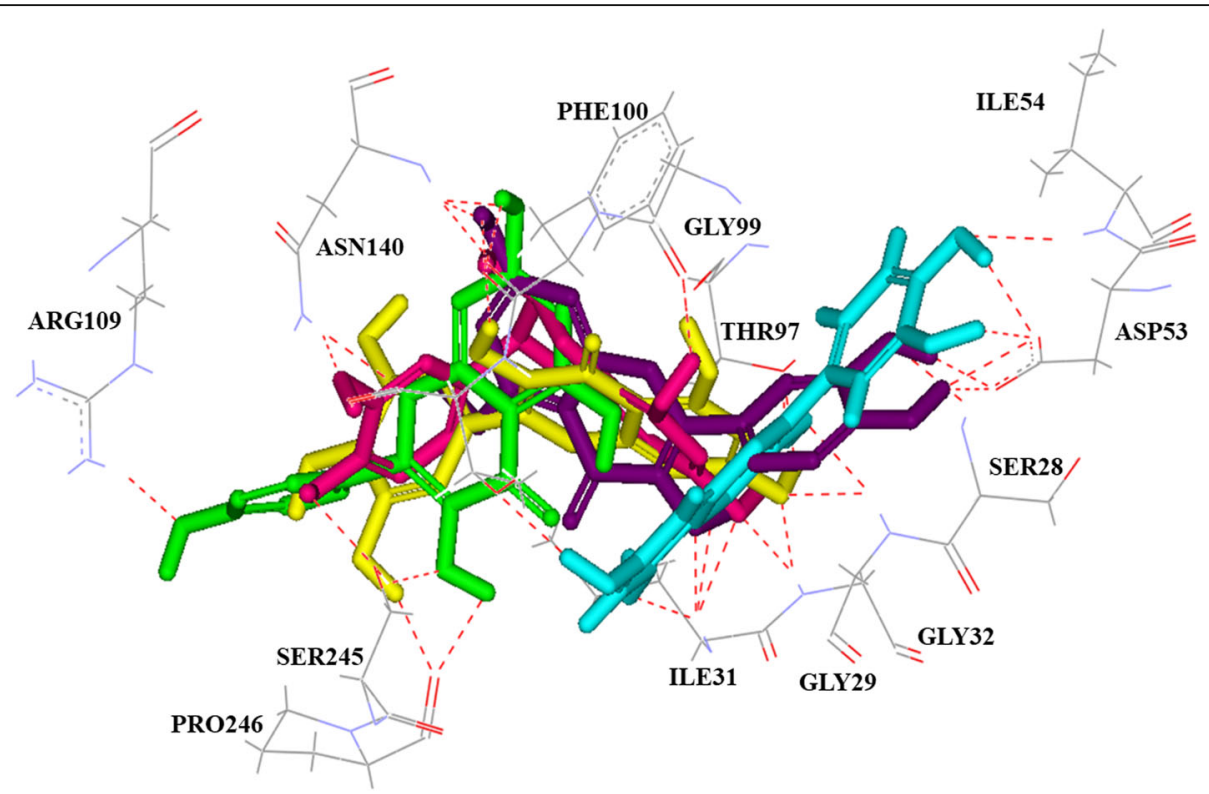

Fig. 3 Superimposed structures of the docked conformations of flavonoid compounds with amino acid residues of PfLDH. 3,5Dimethoxyquercetin (4; purple), (+)-catechin (5; magenta), quercetin (6; cyan), kaempferol (7; green) and myricetin (11; yellow). Hydrogen bond interactions are shown as red dashed lines

perforatum, Sambucus canadensis, Aesculus indica, and Dendrobium officinale [30, 31]. It has been reported to possess various biological activities, including antiinflammatory [32], antioxidant [33], anticancer [34] and anti-HIV integrase activities [21]. Regarding the other Dioscorea species, D. loureiri and D. membranacea have been reported to exhibit antimalarial activity against both $P$. falciparum 3D7 and K1 strains [35].

In an attempt to investigate the mechanism of active compounds against $P$. falciparum, the binding mode of compounds with the target protein of $P$. falciparum was predicted using computational docking. Molecular docking is one of the most frequently used methods to predict the interaction of two molecules in structure-based drug design with a substantial degree of accuracy [36, 37]. In the present study, the PfLDH enzyme was selected for study since it has been considered a potential molecular target for antimalarial drugs because it controls energy production in plasmodium. In addition, this enzyme is found in all five species that cause human malaria, including $P$. falciparum, $P$. vivax, $P$. ovale, $P$. malariae and $P$. knowlesi $[38,39]$. The biological functions of PfLDH and human LDH are very similar, but their amino acid sequences are less similar. Therefore, the selective targeting of this glycolytic enzyme in PfLDH may not disturb human LDH [9].

Regarding $P$. falciparum molecular targets, other $P$. falciparum targets have been proven to be major molecular drug targets of antimalarial drugs. P. falciparum dihydrofolate reductase (PfDHFR), a key enzyme in de novo folate biosynthesis, is considered a known target for malaria. As a result, antifolate antimalarial drugs (pyrimethamine and cycloguanil) inhibit dihydrofolate reductase (DHFR) and interfere with folate metabolism, a pathway essential to malaria parasite survival [40]. Additionally, PfATP6, the SERCA-type $\mathrm{Ca}^{2+}$-ATPase enzyme present in the malarial parasite, has been identified as the molecular target for artemisinin, curcumin and curcumin derivatives [41].

Regarding docking, the predicted binding energy is calculated. A more negative binding energy indicates stronger binding [10]. Docking results in accordance with the in vitro results showed that quercetin, the most potent antimalarial activity against $P$. falciparum, which is characterized by the presence of five hydroxyl groups at positions $3,5,7,3^{\prime}$ and $4^{\prime}$, also possessed strong interactions with PfLDH. It was found to have similar interactions to the standard artesunate, the structure fitted well to the active site, and all of its hydroxyl groups strongly interacted with residues GLY29, ILE31, ASP53, ILE54, THR97 and THR101. The oxygen of the hydroxyl group of this compound extensively contacts ILE31 and ASP53 by forming two hydrogen bonds each. Quercetin showed different binding patterns compared to other flavonoids. It directly pointed to ASP53 and tightly formed hydrogen bonds. These binding pattern differences as well as the high number of hydrogen bonds that formed with PfLDH residues were possible reasons why this compound was active. 
2,4,3', $5^{\prime}$-Tetrahydroxybibenzyl (9), an active compound from an in vitro study, was found to bind preferentially in a similar way to quercetin. All four hydroxyl groups on its structure formed eight hydrogen bonds with residues GLY29, GLY32, THR97, GLY99, PHE100, THR101 and ASN140. The results showed that ohydroxyl structures are the active functional groups for potential inhibitors of PfLDH.

Regarding artesunate, an artemisinin derivative is a sesquiterpene lactone containing an endoperoxide bridge that is essential for the mode of action. The cleavage of the peroxide bridge in the presence of ferrous ions $\left(\mathrm{Fe}^{2+}\right.$ from heme forms a rapid rearrangement to produce carbon-centered free radicals, leading to chemical modification and inhibition of a variety of parasite molecules, resulting in parasite death [42]. Interestingly, the docking results from this study revealed that artesunate also inhibited the PfLDH enzyme by extensively interacting with the active site. Its endoperoxide bridge strongly interacted with ILE54 with two hydrogen bonds, ILE31, GLY29, GLY32, THR97 and GLY99, with a high binding energy $(-11.21 \mathrm{kcal} / \mathrm{mol})$. CQ possessed a weak interaction by forming only one hydrogen bond with GLY99 with a binding energy of $-6.65 \mathrm{kcal} / \mathrm{mol}$, which is similar to a previous report that it forms hydrogen bonds with ASP53 and GLY99 [9].

According to the docking results, GLY29, ILE31, GLY32, ASP53, GLY99, THR101 and ASN140 are the essential residues in the PfLDH active site that participate in the interactions of active inhibitors. These results are in accordance with a previous study reporting that commercially available drugs, including itraconazole, atorvastatin and posaconazole (analogs of NADH, an essential cofactor of $\mathrm{pLDH}$ ), showed the best docking energy values and fit well in the binding pocket of the PfLDH active site. They interact with GLY29, MET30, ILE31, GLY32, ASP53, TYR85, THR97, GLY99, GLU122, ASN140 and SER245 [38].

The results supported the antimalarial activity, and active compounds that inhibited the growth of the $P$. falciparum K1 strain also strongly interacted with the residues in the NADH binding pocket located in the PfLDH active site. Therefore, the mechanism of growth inhibition of $P$. falciparum by the active compounds results from competitive inhibition with $\mathrm{NADH}$ of the PfLDH enzyme [38].

\section{Conclusions}

The present study demonstrated that quercetin is a potential compound responsible for the antimalarial activity of $D$. bulbifera and is an inhibitor of PfLDH. It appears to be an attractive compound for the development of new antimalarial agents. These findings provide more evidence to support the traditional use of $D$. bulbifera for malaria treatment. Structural models of its interactions at the PfLDH active site are plausibly useful for the future design of antimalarial drugs.

\begin{abstract}
Abbreviations
ACTs: Artemisinin-based combination therapies; ATP: Adenosine triphosphate; C: Carbon; CC $_{50}$ : 50\% Cytotoxic concentration; COSY: Correlation Spectroscopy; CQ: Chloroquine; DEPT: Distortionless Enhancement by Polarization Transfer; DMSO: Dimethyl sulfoxide; ElMS: Electron lonization Mass Spectrometer; H: Proton; HMBC: Heteronuclear Multiple Bond Correlation; HMQC: Heteronuclear Multiple Quantum Coherence; $\mathrm{IC}_{50}$ : The half maximal inhibitory concentration; LDH: Lactate dehydrogenase; N: Nitrogen; NADH: Nicotinamide adenine dinucleotide; MTT: 3-[4,5-dimethylthiazol-2-yl]-2,5-diphenyl-tetrazolium bromide; O: Oxygen; PfLDH: Plasmodium falciparum lactate dehydrogenase; WHO: World Health Organization

\section{Acknowledgments}

The authors are grateful to the staff of the Department of Parasitology, Phramongkutklao College of Medicine, Bangkok, Thailand. Additionally, thanks to the Research Institute and Health Science, Walailak University for providing laboratory facilities.
\end{abstract}

\section{Authors' contributions}

PC and CP conceived and design the study. PC, MM, PV and CP performed the research. $P C, P V, M M, A P$ and $C P$ analyzed and interpreted the research data. AP and MM provided significant suggestions on the methodology. PC, $M M$ and $C P$ wrote a first draft of manuscript. The authors contributed to the review and approved the final version of the manuscript.

\section{Funding}

This research was supported by The Agricultural Research Development Agency (Public Organization), Grant No. CRP6205031670.

\section{Availability of data and materials \\ The data associated with this study are included in this published article. Additional files are available from the corresponding author upon reasonable request.}

\section{Declarations}

Ethics approval and consent to participate

Ethical approval for this study was obtained from the Human Research Ethics Committee of Walailak University prior to the recruitment of any participants (Approval number: WUEC-19-126-01).

\section{Consent for publication}

Not applicable.

\section{Competing interests}

The authors declare that they have no competing interests regarding the publication of this paper.

\section{Author details}

${ }^{1}$ School of Medicine, Walailak University, Nakhon Si Thammarat 80160, Thailand. ${ }^{2}$ Department of Parasitology, Phramongkutklao College of Medicine, Bangkok 10400, Thailand. ${ }^{3}$ School of Science, Walailak University, Nakhon Si Thammarat 80160, Thailand. ${ }^{4}$ Department of Tropical Pathology, Faculty of Tropical Medicine, Mahidol University, Bangkok 10400, Thailand.

Received: 13 January 2021 Accepted: 6 May 2021

Published online: 18 May 2021

\section{References}

1. Fenta M, Kahaliw W. Evaluation of antimalarial activity of hydromethanolic crude extract and solvent fractions of the leaves of Nuxia congesta R. Br. Ex Fresen (Buddlejaceae) in Plasmodium berghei infected mice. J Exp Pharmacol. 2019;11:121-34. https://doi.org/10.2147/JEP.S230636.

2. Geleta G, Ketema T. Severe malaria associated with Plasmodium falciparum and $P$. vivax among children in Pawe hospital, Northwest Ethiopia. Malar Res Treat. 2016;2016:1240962. 
3. Conrad MD, Rosenthal PJ. Antimalarial drug resistance in Africa: the calm before the storm? Lancet Infect Dis. 2019;19(10):e338-e51. https://doi.org/1 0.1016/S1473-3099(19)30261-0.

4. WHO. World malaria report. Geneva: World Health Organization; 2019.

5. Oboh MA, Ndiaye D, Antony HA, Badiane AS, Singh US, Ali NA, et al. Status of artemisinin resistance in malaria parasite Plasmodium falciparum from molecular analyses of the Kelch13 gene in southwestern Nigeria. Biomed Res Int. 2018;2018:2305062.

6. Menard D, Dondorp A. Antimalarial drug resistance: a threat to malaria elimination. Cold Spring Harb Perspect Med. 2017;7(7):a025619. https://doi org/10.1101/cshperspect.a025619.

7. Monika C, Reena R, Dushyant S, Jaya Parkash Y. Antimalarial activity of Curcuma Caesia against 3D7 and K1 strains of Plasmodium Falciparum. Res Square. 2020. https://doi.org/10.21203/rs.3.rs-32452/v2.

8. Uzor PF. Alkaloids from plants with antimalarial activity: a review of recent studies. Evid Based Complement Alternat Med. 2020;2020:8749083.

9. Singh $R$, Bhardwaj $V$, Purohit R. Identification of a novel binding mechanism of quinoline based molecules with lactate dehydrogenase of Plasmodium falciparum. J Biomol Struct Dyn. 2020;39:1-9.

10. Muttaqin SS, Maji JS. Screening of oxamic acid similar 3D structures as candidate inhibitor Plasmodium falciparum L-lactate dehydrogenase of malaria through molecular docking. In: 1st International conference on bioinformatics, biotechnology, and biomedical engineering - bioinformatics and biomedical engineering; 2018.

11. Ntie-Kang F, Onguéné PA, Lifongo LL, Ndom JC, Sippl W, Mbaze LM. The potential of anti-malarial compounds derived from African medicinal plants, part II: a pharmacological evaluation of non-alkaloids and non-terpenoids. Malar J. 2014;13:81

12. Jones RA, Panda SS, Hall CD. Quinine conjugates and quinine analogues as potential antimalarial agents. Eur J Med Chem. 2015;97:335-55. https://doi. org/10.1016/j.ejmech.2015.02.002.

13. Brown GD. The biosynthesis of artemisinin (Qinghaosu) and the phytochemistry of Artemisia annua L. (Qinghao). Molecules. 2010;15(11): 7603-98. https://doi.org/10.3390/molecules15117603.

14. Raphael RM, John B, Mariat G, Minj E. Pharmacognostic, fluorescent, antibacterial and phytochemical analysis of tuber of Dioscorea bulbifera $\mathrm{L}$. from Jharkhand. J Pharmacogn Phytochem. 2016;5(1):8-14.

15. Ghosh S, Ahire M, Patil S, Jabgunde A, Bhat Dusane M, Joshi BN, et al. Antidiabetic activity of Gnidia glauca and Dioscorea bulbifera: potent amylase and glucosidase inhibitors. Evid Based Complement Altern Med. 2012;2012:929051

16. Mbiantcha M, Kamanyi A, Teponno R, Tapondjou A, Watcho P, Nguelefack TB. Analgesic and anti-inflammatory properties of extracts from the bulbils of Dioscorea bulbifera L. var sativa (Dioscoreaceae) in mice and rats. Evid Based Complement Altern Med. 2011;2011:912935.

17. Savi A, Calegari G, Santos V, Pereira E, Teixeira S. Chemical characterization and antioxidant of polysaccharide extracted from Dioscorea bulbifera. J King Saud Univ Sci. 2018;32:636-42.

18. Okigbo RN, Anuagasi CL, Amadi JE, Ukpabi UJ. Potential inhibitory effects of some African tubereous plant extracts on Escherichia coli, Staphylococcus aureus and Candida albicans. Int J Integr Biol. 2009;6(2):91-8.

19. Ahmed Z, Chishti M, Johri R, Bhagat A, Gupta K, Ram G. Antihyperglycemic and antidyslipidemic activity of aqueous extract of Dioscorea bulbifera tubers. Diabetol Croat. 2009;38:63-72.

20. Chaniad P, Wattanapiromsakul C, Pianwanit S, Tewtrakul S. Anti-HIV-1 integrase compounds from Dioscorea bulbifera and molecular docking study. Pharm Biol. 2016;54(6):1077-85. https://doi.org/10.3109/13880209.201 5.1103272

21. Chaniad P, Chatchai W, Pianwanit S, Tewtrakul S. Inhibitors of HIV-1 integrase from Dioscorea bulbifera. Songklanakarin J Sci Technol. 2016;38: 229-36.

22. Trager $\mathbf{W}$, Jensen JB. Human malaria parasites in continuous culture. Science. 1976;193(4254):673-5.

23. Phuwajaroanpong A, Chaniad P, Horata N, Muangchanburee S, Kaewdana K, Punsawad C. In vitro and in vivo antimalarial activities and toxicological assessment of Pogostemon cablin (Blanco) Benth. J Evid Based Integr Med. 2020;25:2515690×20978387

24. Desjardins RE, Canfield CJ, Haynes JD, Chulay JD. Quantitative assessment of antimalarial activity in vitro by a semiautomated microdilution technique. Antimicrob Agents Chemother. 1979;16(6):710-8. https://doi.org/10.1128/AA C.16.6.710.
25. Tahghighi A, Mohamadi-Zarch S-M, Rahimi H, Marashiyan M, Maleki-Ravasan $\mathrm{N}$, Eslamifar A. In silico and in vivo anti-malarial investigation on 1(heteroaryl)-2-((5-nitroheteroaryl)methylene) hydrazine derivatives. Malaria J. 2020;19(1):231. https://doi.org/10.1186/s12936-020-03269-7.

26. Salentin S, Schreiber S, Haupt VJ, Adasme MF, Schroeder M. PLIP: fully automated protein-ligand interaction profiler. Nucleic Acids Res. 2015; 43(W1):W443-W7. https://doi.org/10.1093/nar/gkv315.

27. Fairhurst RM, Dondorp AM. Artemisinin-resistant Plasmodium falciparum malaria. Microbiol Spectr. 2016:4(3):409-29.

28. Pattaradilokrat S, Sawaswong V, Simpalipan P, Kaewthamasorn M, Siripoon $\mathrm{N}$, Harnyuttanakorn P. Genetic diversity of the merozoite surface protein-3 gene in Plasmodium falciparum populations in Thailand. Malaria J. 2016; 15(1):517. https://doi.org/10.1186/s12936-016-1566-1.

29. Ganesh D, Fuehrer HP, Starzengrüber P, Swoboda P, Khan WA, Reismann JA, et al. Antiplasmodial activity of flavonol quercetin and its analogues in Plasmodium falciparum: evidence from clinical isolates in Bangladesh and standardized parasite clones. Parasitol Res. 2012;110(6):2289-95. https://doi. org/10.1007/s00436-011-2763-Z

30. Li Y, Yao J, Han C, Yang J, Chaudhry MT, Wang S, et al. Quercetin, inflammation and immunity. Nutrients. 2016;8(3):167.

31. Zahoor M, Shafiq S, Ullah H, Sadiq A, Ullah F. Isolation of quercetin and mandelic acid from Aesculus indica fruit and their biological activities. BMC Biochem. 2018;19(1):5

32. Lee HN, Shin SA, Choo GS, Kim HJ, Park YS, Kim BS, et al. Anti-inflammatory effect of quercetin and galangin in LPS-stimulated RAW264.7 macrophages and DNCB-induced atopic dermatitis animal models. Int J Mol Med. 2018; 41(2):888-98. https://doi.org/10.3892/ijmm.2017.3296.

33. Xu D, Hu MJ, Wang YQ, Cui YL. Antioxidant activities of quercetin and its complexes for medicinal application. Molecules. 2019;24(6):1123.

34. Nguyen LT, Lee $Y-H$, Sharma AR, Park J-B, Jagga $S$, Sharma $G$, et al. Quercetin induces apoptosis and cell cycle arrest in triple-negative breast cancer cells through modulation of Foxo3a activity. Korean J Physiol Pharmacol. 2017;21(2):205-13. https://doi.org/10.4196/kjpp.2017.21.2.205.

35. Thiengsusuk A, Chaijaroenkul W, Na-bangchang K. Antimalarial activities of medicinal plants and herbal formulations used in Thai traditional medicine. Parasitol Res. 2013;112(4):1475-81. https://doi.org/10.1007/s00436-013-32946.

36. Ferreira L, Santos R, Oliva G, Andricopulo A. Molecular docking and structure-based drug design strategies. Molecules. 2015;20(7):13384-421. https://doi.org/10.3390/molecules200713384.

37. Pinzi L, Rastelli G. Molecular docking: shifting paradigms in drug discovery. Int J Mol Sci. 2019;20(18):4331. https://doi.org/10.3390/ijms20184331.

38. Penna-Coutinho J, Cortopassi WA, Oliveira AA, França TCC, Krettli AU. Antimalarial activity of potential inhibitors of Plasmodium falciparum lactate dehydrogenase enzyme selected by docking studies. PLoS One. 2011;6(7): e21237.

39. Jeremiah S, Janagond AB, Parija SC. Challenges in diagnosis of Plasmodium knowlesi infections. Trop Parasitol. 2014;4(1):25-30. https://doi.org/10.41 03/2229-5070.129156.

40. Singh IV, Mishra S. Molecular docking analysis of Pyrimethamine derivatives with Plasmodium falciparum Dihydrofolate Reductase. Bioinformation. 2018; 14(5):232-5. https://doi.org/10.6026/97320630014232.

41. Dohutia C, Chetia D, Gogoi K, Bhattacharyya DR, Sarma K. Molecular docking, synthesis and in vitro antimalarial evaluation of certain novel curcumin analogues. Braz J Pharm Sci. 2017;53(4):e00084. https://doi.org/1 0.1590/s2175-97902017000400084.

42. Shandilya A, Chacko S, Jayaram B, Ghosh I. A plausible mechanism for the antimalarial activity of artemisinin: a computational approach. Sci Rep. 2013; 3(1):2513. https://doi.org/10.1038/srep02513.

\section{Publisher's Note}

Springer Nature remains neutral with regard to jurisdictional claims in published maps and institutional affiliations. 